\title{
Editorial
}

https://doi.org/10.3348/kjr.2018.19.1.4

pISSN 1229-6929 · eISSN 2005-8330

Korean J Radiol 2018;19(1):4-4

\section{Announcement of New Deputy Editor}

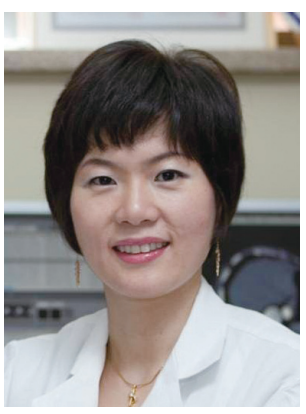

\section{Dear colleagues,}

We are pleased to announce the new deputy editor, Dr. Se Hyung Kim of Seoul National University, College of Medicine. Dr. Se Hyung Kim graduated magna cum laude from Seoul National University, School of Medicine. She then earned her MD degree in 1996 from the same university. After an internship at Seoul National University Hospital (SNUH), she pursued residency training in radiology at SNUH. Dr. Kim is certified in Diagnostic Radiology by the Korean Board of Radiology. She subsequently spent one and half years in her fellowship training in abdominal radiology at the same institution. On completion of that training in Aug. of 2002, she became a member of the Department of Radiology at SNUH initially as a clinical instructor, after which she was promoted to being first an assistant and then, an associate professor. Since March 2017, she has been a professor of the Department of Radiology at SNUH. She has been an outstanding reviewer for several journals, including the Korean Journal of Radiology and Radiology. She received the Radiology Editor's Recognition Award with Distinction in 2008-2010 and 2013. In 2013, she was appointed as an Associate Editor of Abdominal Imaging. She has more than 280 scientific publications (including $236 \mathrm{SCI}(\mathrm{E})$ publications) to her credit, as well as 11 book chapters. Her list of scientific presentations indicates sustained efforts in radiologic research since 1999 at both national and international meetings. She has delivered many invited international and regional lectures. She has participated in many research projects that have received grant support. 